\title{
Short communication: Proinflammatory gene expression relative to the collection technique of endometrial samples from cows with and without subclinical endometritis
}

\author{
Nadia S. Fagundes, ${ }^{1,2}$ Amanda L. Rezende, ${ }^{1}$ Paula B. Alvarenga, ${ }^{1}$ Layane Q. Magalhães, ${ }^{1}$ Ricarda M. Santos, ${ }^{1}$ \\ Selwyn A. Headley, ${ }^{3}$ Marcelo J. B. Silva, ${ }^{2}$ Marcelo E. Beletti, ${ }^{2}$ and João P. E. Saut ${ }^{1 *}$ \\ ${ }^{1}$ Large Animal Health Laboratory, Federal University of Uberlândia, Uberlândia-Minas Gerais, 38400-902, Brazil \\ ${ }^{2}$ Laboratory of Biology of Reproduction, Instituto de Ciências Biomédicas, Federal University of Uberlândia, Uberlândia-Minas Gerais, 38400-902, \\ Brazil \\ ${ }^{3}$ Laboratory of Animal Pathology, Department of Veterinary Preventive Medicine, Universidade Estadual de Londrina, Paraná, 86057-970, Brazil
}

\section{ABSTRACT}

Uterine inflammation negatively affects reproductive performance and is an important cause of infertility and subfertility in dairy cows. Several studies have investigated the use of gene expression in endometrial samples collected by biopsy or cytology to evaluate the inflammatory response of the cow uterus. This study aimed to compare the expression of the CCL5, CXCL8,IL6, and $I L 1 B$ genes in the bovine endometrium according to the site of sample collection [caruncular (C) or intercaruncular (IC)], the collection method (biopsy or cytology), and the category of inflammation based on endometrial cytology (zero, medium, or high) in subclinical endometritis. The reproductive tracts of dairy cows were collected from a slaughterhouse, and punch-biopsy samples of endometrial tissues were obtained from both regions (C and IC). Endometrial cells from these regions were collected with the cytobrush technique and then used for the analysis of mRNA expression by quantitative PCR. After counting polymorphonuclear cells (PMN) by endometrial cytology, 20 uteri with an ovary at stage I (d 1-4 of estrous cycle) were categorized into 3 groups. Uteri with $0 \%$ PMN $(\mathrm{n}=10)$ were assigned to group zero, uteri with 5 to $15 \% \mathrm{PMN}(\mathrm{n}=5)$ to group medium $(12.2 \pm 1.6 \% \mathrm{PMN})$, and uteri with $>15 \%$ PMN $(\mathrm{n}=5)$ to group high $(53.8 \pm 32.9 \%$ PMN $)$. All data were analyzed with 2-way ANOVA with Bonferroni multiple comparison post test. The results from gene transcripts demonstrated that the region (C or IC) of the endometrial biopsy had no influence on any of the degrees of inflammatory reaction observed. However, gene expression was more elevated in the endometrium

Received June 14, 2018.

Accepted February 18, 2019.

*Corresponding author: jpsaut@ufu.br of cows with greater inflammation compared with those without inflammation $(C C L 5, C X C L 8, I L 6, I L 1 B)$ and those with medium inflammation $(C C L 5, I L 6)$. Expression of the genes evaluated did not differ between the endometrium without inflammation and with medium inflammation. However, in the high inflammation group, all genes were comparatively more expressed in samples collected by cytology relative to those derived from biopsies for both anatomical regions. In conclusion, gene expression did not differ between the $\mathrm{C}$ and IC tissue. Samples collected from animals with greater inflammation had greater gene expression than those with zero or medium inflammation. In addition, cytology samples had greater gene expression than biopsy samples in the high inflammation group.

Key words: biopsy, caruncular region, cytobrush, endometrium, intercaruncular region

\section{Short Communication}

Uterine inflammation causes a negative effect on reproductive performance and is an important cause of infertility and subfertility in dairy cattle herds (Sheldon et al., 2009). This inflammatory process can result in reduced pregnancy rate and increases in the calvingconception interval, the number of inseminations per gestation (Kasimanickam et al., 2004; Sheldon et al., 2009), and the incidence of repeat breeder cows (Salasel et al., 2010).

The endometrium regulates the inflammatory response through the production and release of cytokines and chemokines (Galvão et al., 2011) that attract and activate hematopoietic immune cells to combat the local infection (Turner et al., 2012). Several proinflammatory cytokines are involved in the inflammatory process in cattle, including IL-1 $\beta$ (Fischer et al., 2010), IL6 (Ishikawa et al., 2004; Fischer et al., 2010), C-C motif chemokine ligand 5 (CCL5; Rebourcet et al., 2010), 
and C-X-C motif chemokine ligand 8 (CXCL8; Fischer et al., 2010; Galvão et al., 2011; Ghasemi et al., 2012). In cows with subclinical endometritis, the gene expression profile was found to indicate an active immune response within a proinflammatory uterine environment (Walker et al., 2015).

Subclinical endometritis is primarily diagnosed by endometrial cytology using the percentage of PMN relative to the sample of endometrial epithelial cells. The threshold values of PMN vary according to the DIM for the diagnosis of subclinical endometritis and are between 5 and $18 \%$, with a general threshold of $5 \%$ being the most widely accepted (Wagener et al., 2017). This was also observed in grazing dairy cows between 21 and 62 DIM (Madoz et al., 2013).

Endometrial biopsy is considered an adequate method to evaluate postpartum uterine alterations or health in cattle (Chapwanya et al., 2010). This technique collects sufficient endometrial tissue for cellular and molecular analyses (Chapwanya et al., 2010). Alternatively, the endometrial brush technique (cytobrush) is a rapid, easy, and noninvasive method to obtain biological material for cytological evaluation and molecular analyses (Ghasemi et al., 2012). Moreover, the cytobrush technique can be used for sequential endometrial gene expression (Cardoso et al., 2017). Several studies have investigated gene expression in bovine reproduction by evaluating the uterine inflammatory response in live animals, using biological samples collected by uterine biopsy (Herath et al., 2009; Galvão et al., 2011) or by cytobrush (Kasimanickam et al., 2004; Barlund et al., 2008; Fischer et al., 2010; Salasel et al., 2010; Ghasemi et al., 2012; Bogado Pascottini et al., 2016).

The percentage of PMN derived from endometrial samples collected by cytobrush influences the gene expression of proinflammatory cytokines (Fischer et al., 2010; Ghasemi et al., 2012), and the cellular composition of biopsy samples differs from that obtained by the cytobrush technique (Cardoso et al., 2017). Saut et al. (2014) have shown that when ex vivo endometrial culture was challenged with LPS or Escherichia coli, the production of proinflammatory cytokines differed between the caruncular (C) and intercaruncular (IC) regions. However, few data are available regarding the variation in gene expression of proinflammatory cytokines between the $\mathrm{C}$ and $\mathrm{IC}$ regions of the endometrium and between the methods of endometrial tissue collection (biopsy or cytology). Data are also lacking on the percentage of PMN in subclinical endometritis.

The aim of this study was to compare the expression of the genes CCL5, CXCL8, IL6, and IL1B in the bovine endometrium according to the site of collection of endometrial samples (C or IC), the collection method (biopsy or cytology), and the category of inflammation based on endometrial cytology (zero, medium, or high).

The uteri of 64 nonpregnant dairy cows were collected from a small commercial slaughterhouse in the city of Uberlândia, Brazil. According to inclusion criteria, reproductive tracts had to be derived from nulliparous or primiparous cows with complete uterine involution, without gross evidence of genital disease or microbial infection (metritis, cervicitis, or clinical endometritis), and more than $60 \mathrm{~d}$ postpartum. The requirement for cows to be more than 60 DIM was based on (1) the reduction of possible variables related to uterine involution and inflammation; (2) the elimination of contaminants during puerperium; and (3) the effect of the positive energy balance during this period. The postpartum period of these cows was known because we had unrestricted access to all data on them. Furthermore, gross evaluations of the uteri at the slaughterhouse corroborated the data received from the dairy farmers, which ensured that all cows included in the study were more than 60 DIM. Genital tracts were selected from animals on d 1 to 4 of the estrous cycle when an ovary contained a recently ruptured follicle (ovarian stage I), as described by Ireland et al. (1979).

The samples were collected immediately after slaughter. The external surface of the uterus was washed with $70 \%$ alcohol, and a random longitudinal incision was made in one of the uterine horns with sterile scissors to expose the endometrium. Endometrial specimens for biopsy, derived from regions $\mathrm{C}$ and IC, were collected by using a sterile punch (Kruuse, Langeskov, Denmark) according to Borges et al. (2012); thereafter, all samples were placed in 2-mL cryotubes (Sarstedt, Numbrecht, Germany) and maintained in liquid nitrogen at $-196^{\circ} \mathrm{C}$ until used in the analysis of mRNA expression of the selected genes. The $\mathrm{C}$ and IC regions were identified as described by Abdel-Raouf and Badawi (1966). The endometrial brush (Labor Import, Osasco, Brazil) was used to collect endometrial tissue from both regions under study (C and IC) simultaneously (i.e., during the same collection) for cytological evaluation and RNA extraction. The brushes were sectioned to fit within the 2 -mL cryotubes, and the collected samples were maintained in liquid nitrogen at $-196^{\circ} \mathrm{C}$ until analysis of the mRNA expression of the selected genes. Both samples (biopsy and cytology) were collected from the same uterine horn, but not at the same anatomic location.

The degree of endometrial inflammation was classified by the endometrial cytology and categorized into 3 groups based on a classification adapted from Kaufmann et al. (2009). All samples were then classified according to the proportion of PMN and divided into group zero with $0 \%$ PMN, group medium with 5 
to $15 \%$, and group high with $>15 \%$. A threshold of 5 to $15 \%$ PMN was used for the medium group in this study, and not $>0-15 \%$ as previously proposed (Kaufmann et al., 2009), because the threshold of $5 \%$ is the most widely accepted for the diagnosis of subclinical endometritis (Madoz et al., 2013; Wagener et al., 2017).

The extraction of RNA derived from the uterine tissue was done using Maxwell 16 Instrument (Promega, Madison, WI), with a commercial RNA tissue extraction kit Maxwell 16 LEV Simply RNA Tissue Kit (reference AS1340, Promega), according to the manufacturer's instructions. The biopsy fragments were weighed (maximum $50 \mathrm{mg}$ ) and macerated in 200 $\mu \mathrm{L}$ of homogenization solution with the aid of Pellet Pestles (Sigma Aldrich, St. Louis, MO). For the cytology samples, $200 \mu \mathrm{L}$ of homogenization solution was added to the microtubes containing the cytobrush, and the mixture was centrifuged to recover the uterine secretion. The total RNA was quantified on the Quantus Fluorometer using the QuantiFluor RNA System kit (reference E3310, Promega) according to the manufacturer's instructions. All RNA samples obtained were maintained in at $-80^{\circ} \mathrm{C}$ until reverse transcription.

Reverse transcription was performed using the kit GoScript Reverse Transcription System (reference A5001, Promega). All steps were done according to the manufacturer's recommendations. The cDNA of each sample was quantified on the Quantus Fluorometer using the Quantifluor ssDNA System kit (reference E3190, Promega) as instructed by the manufacturer and maintained at $-20^{\circ} \mathrm{C}$ until used in real-time PCR. The quantification of $I L 1 B, I L 6, C X C L 8$, and CCL5 gene expression was performed with the 7300 RealTime PCR System (Applied Biosystems, Foster, CA) using the threshold cycles (Ct) method. Throughout the experiment, 96-well PCR-96 AB-C plates (Axygen Scientific, Union City, CA) were used and all amplifications were done in duplicate with 1 negative control included for each gene under evaluation and SUZ12 as the housekeeping gene. For the reaction, the Quantinova SYBR Green PCR kit (Qiagen, Valencia, CA) was used. The primers used for the amplification of the $I L 1 B, I L 6, C X C L 8$, and $C C L 5$ genes are shown in Table 1 (Saut et al., 2014). The efficiency curve of the primers was performed with 4 points and a 1:2 dilution factor, starting with a concentration of $855 \mathrm{ng}$ of cDNA. The housekeeping gene SUZ12 was selected as described by Walker et al. (2009).

The experiment was done to assess 2 variables: sample collection method (cytobrush, biopsy of the $\mathrm{C}$ region, and biopsy of the IC region) and status of uterine inflammation (zero, medium, and high). All statistical analyses were performed using the Graph-
Pad Prism statistical package (GraphPad Software, La Jolla, CA), with animal as the experimental unit. All data were submitted to the Kolmogorov-Smirnov test to determine whether the groups had a normal distribution, with the nonparametric data being transformed into $\log _{10}$ (variable). The gene expression values were separated into groups based on the experiments realized and 2-way ANOVA with Bonferroni multiple comparison post test was then performed. Data are presented as mean \pm standard error of the mean, and differences were considered when $P<0.05$.

Twenty uteri met the inclusion criteria for this study. Ten uteri with $0 \%$ PMN were assigned to group zero, 5 uteri with 5 to $15 \%$ PMN to group medium (12.2 \pm $1.6 \% \mathrm{PMN}$ ), and 5 uteri with $>15 \% \mathrm{PMN}$ to group high $(53.8 \pm 32.9 \%$ PMN; Figure $1 \mathrm{~A}$ and $\mathrm{B})$. The fragments obtained by endometrial biopsies (Figure $1 \mathrm{C}$ and D), collected with the aid of the punch $(8 \mathrm{~mm})$, had weights varying between 32 and $116 \mathrm{mg}(69.9 \pm 20)$ and yielded an average RNA concentration of 131.7 $\pm 60.1 \mathrm{ng} / \mu \mathrm{L}$ after extraction. The averages for the samples derived from the $\mathrm{C}$ and IC areas were 133.4 \pm 67.5 and $130.0 \pm 53.0 \mathrm{ng} / \mu \mathrm{L}$, respectively. Samples collected with the cytobrush had an average $175.9 \pm$ $66.4 \mathrm{ng} / \mu \mathrm{L}$ of extracted RNA.

We observed no differences in the gene expression of the proinflammatory cytokines evaluated for the $\mathrm{C}$ and IC regions (Figure 2), regardless of the PMN percentage (zero, medium, or high). These results were in contrast to findings from ex vivo endometrial cultures of the $\mathrm{C}$ and IC regions challenged with LPS or E. coli, in which the concentrations of the cytokines IL1B, IL6, and CXCL8 were comparatively higher in the IC relative to the $\mathrm{C}$ region (Saut et al., 2014). Differences in gene expression between the $\mathrm{C}$ and $\mathrm{IC}$ regions were also described in studies that investigated implantation and embryonic development in cattle and sheep (MansouriAttia et al., 2009; Al-Gubory et al., 2014). Because the

Table 1. Primer sequences used for the amplification of mRNA of the genes evaluated by quantitative reverse-transcription PCR

\begin{tabular}{lll}
\hline Gene & $\begin{array}{l}\text { Primer } \\
\text { direction }\end{array}$ & Primer sequence $\left(5^{\prime}\right.$ to $\left.3^{\prime}\right)$ \\
\hline$I L 1 B$ & Forward & TCCTATTCTCTCCAGCCA \\
& Reverse & AGCCTCAAATAACAGCTCATTC \\
IL6 & Forward & ATGACTTCTGCTTTCCCTACCC \\
& Reverse & GCTGCTTTCACACTCATCATTC \\
CXCL8 & Forward & CACATTCCACACCTTTCCAC \\
& Reverse & CCTTCTGCACCCACTTTTC \\
CCL5 & Forward & CTTTGCCTATATCTCCCGCC \\
& Reverse & TCTCGCACCCACTTCTTCTC \\
SUZ12 & Forward & GAAGATGGAGAAGTGGAACA \\
& Reverse & GACGGAGAGGTAAACAAGTATC \\
\hline
\end{tabular}


data obtained in this study are different from those of previously published studies, additional investigations with other cytokines and with a larger number of samples are necessary to avoid the possibility of type II statistical errors and to verify our results.

The study results (Figure 2) showed that $I L 1 B, I L 6$, $C X C L 8$, and CCL5 mRNA expression was similar between endometrial samples from the zero and medium groups, demonstrating that the expression of these genes was not related to the percentage of PMN in the endometrium that had a slight degree of inflammation. These results accord with those of Fischer et al. (2010), who considered the cutoff point of $>5 \%$ PMN for subclinical endometritis and did not identify any difference in the expression of $I L 6$ and $C X C L 8$ between cows with and without subclinical endometritis, with a difference observed only for the $I L 1 B$ gene. These results are consistent with Ghasemi et al. (2012), who reported that $18 \% \mathrm{PMN}$ was the threshold above which gene expression was significantly elevated for the proinflammatory mediators IL6, CXCL8, and tumor necrosis factor $(\mathrm{TNF}) \alpha$.

The most commonly used studies that defined cutoff points below 15\% PMN for the diagnosis of subclinical endometritis used $>3 \%$ (Salasel et al., 2010), >6.5\% (Galvão et al., 2009), and $>5 \%$ neutrophils (Gilbert et al., 2005; Fischer et al., 2010). According to our results, the use of gene expression of proinflammatory mediators is not recommended using the cutoff points cited above because these values cannot be used to differentiate between cows with and without subclinical endometritis.

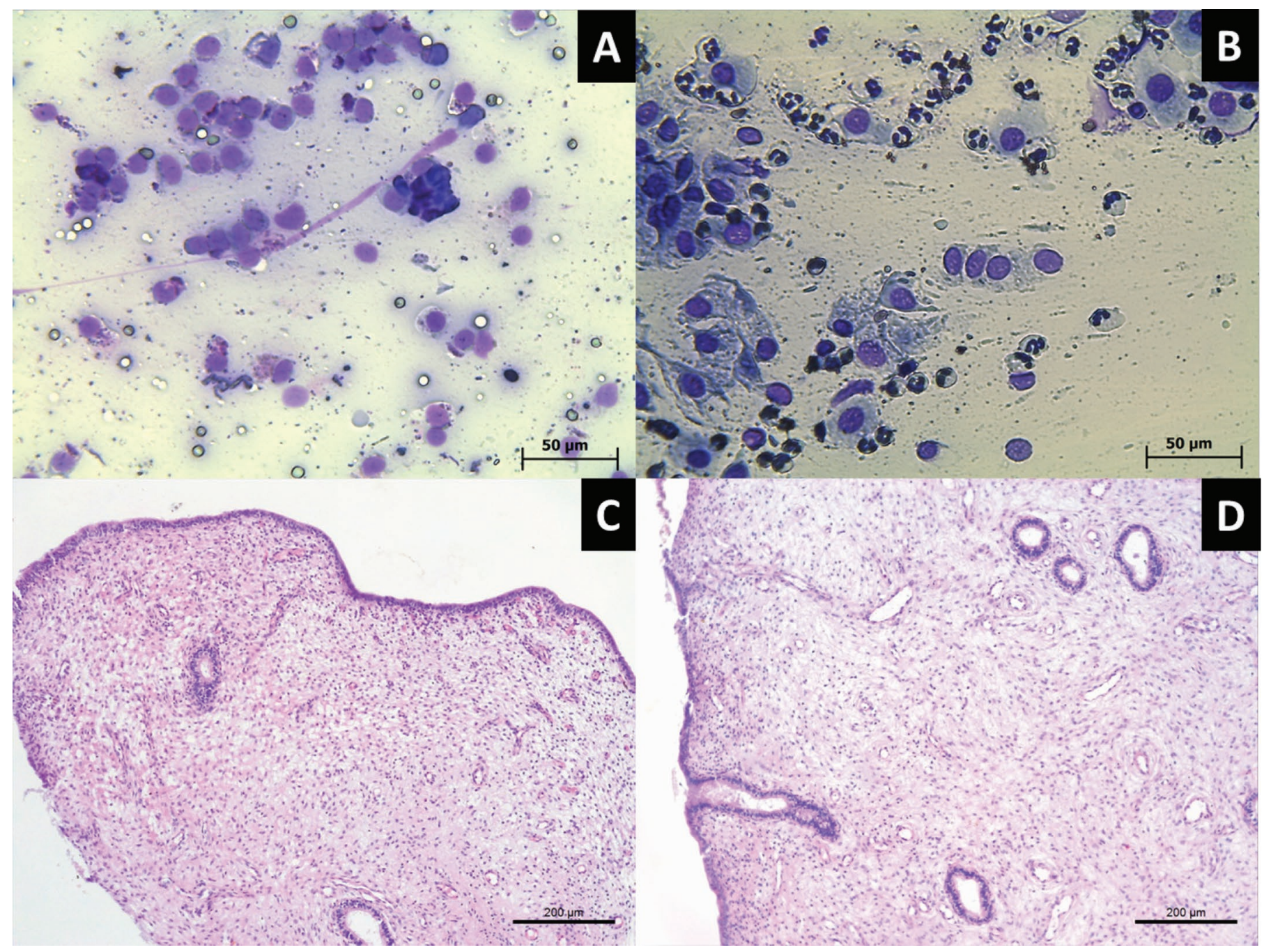

Figure 1. Cytological evaluation of uterus samples classified as without inflammation (A) compared with a uterine sample with an elevated percentage of PMN (inflammatory reaction; (B). Histologic comparison between uterine samples taken with punch in the caruncular (C) and intercaruncular (D) regions. 


\section{Caruncular biopsy $\square$ Intercaruncular biopsy $\square$ Endometrial cytology}

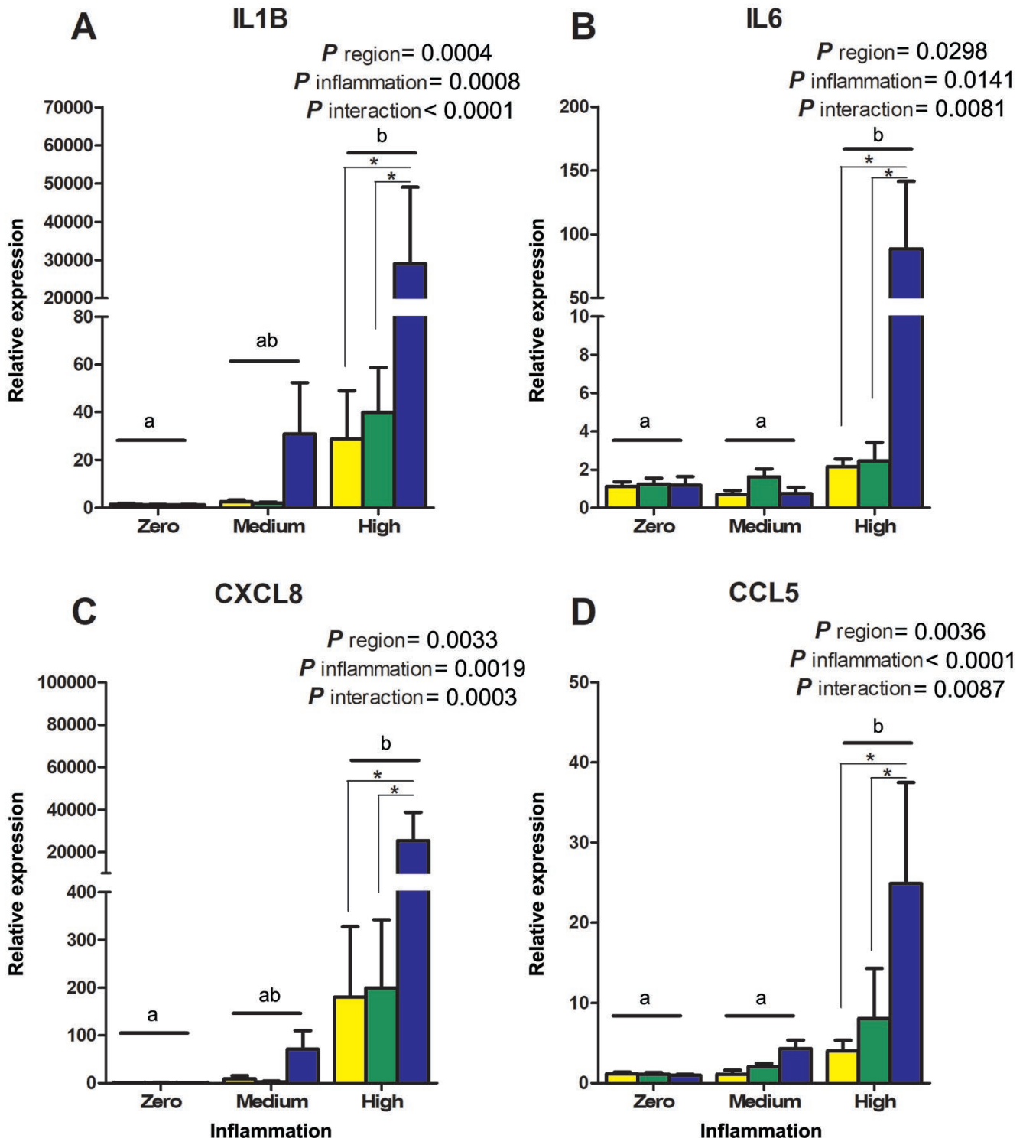

Figure 2. Transcripts for relative expression of the $I L 1 B, I L 6, C X C L 8$, and $C C L 5$ genes in samples collected by cytobrush (endometrial cytology), caruncular biopsy, and intercaruncular biopsy of the endometrial mucosa of cows with zero $(\mathrm{n}=10)$, medium $(\mathrm{n}=5)$, and high $(\mathrm{n}=$ 5) inflammatory reaction. The level of inflammation was determined by the cytobrush technique, where zero inflammation $=0 \%$ PMN, medium inflammation $=5$ to $15 \%$ PMN, and high inflammation $=>15 \%$ PMN. The results are presented in mean \pm standard error of the mean and analyzed by 2-way ANOVA and Bonferroni multiple comparison post test, with different values between groups (a, b) when $P<0.05$. Letters show differences across inflammation classes, and asterisks show differences with an inflammation class across sample collection method.

However, in studies in which a percentage cutoff above $15 \%$ was used (Kasimanickam et al., 2005; Sheldon et al., 2008; Ghasemi et al., 2012), the evaluation of IL1B, IL6, CXCL8, and CCL5 expression was suggested as a means to differentiate cows with and without subclinical endometritis. Importantly, our results were obtained from the uteri of cows with subclinical endometritis and more than 60 DIM, during which uterine involution is normally established, a completely different circumstance from postpartum cows with subclinical endometritis between 21 and 42 DIM.

When the count of PMN was elevated $(>15 \%)$, indicating greater endometrial inflammation, gene expression differed relative to that of endometrial samples with zero and medium inflammatory reactions (Figure 2). These differences were observed in samples collected by biopsy or cytology, and they highlight the importance of knowing the percentage of PMN in the samples 
and not only determining minimum cutoff points for the diagnosis of subclinical endometritis.

In a comparison of the cases with greater inflammation, the samples collected by cytology presented the highest levels of expression of the proinflammatory genes evaluated relative to those obtained by $\mathrm{C}$ or IC endometrial biopsy. Ghasemi et al. (2012) showed that the cytobrush technique results in the recovery of endometrial epithelial cells and infiltrated PMN that provide adequate RNA for analysis of the gene expression at the interface between uterus and uterine lumen. However, cytobrush samples differed from endometrial biopsies that may have contained multiple uterine layers.

According to Chapwanya et al. (2010), the difference between sample types is because endometrial biopsies include the endometrial and stromal layers, and leukocytic infiltration is more intense as the inflammatory response increases. Consequently, the biopsy specimens are likely to have a lower concentration of inflammatory cells and related gene expression associated with the inflammatory process relative to cytobrush samples because the inflammatory reaction frequently begins in the more superficial layers that are exposed to irritants (Chapwanya et al., 2010).

Polymorphonuclear cells are the predominant type of inflammatory cells found in uterine fluid and are considered the first innate immune system response to an infection. Moreover, the intensity of the inflammatory process is directly related to the greater recruitment of PMN, mainly neutrophils, to the uterine lumen and infiltration into the endometrial tissue (LeBlanc et al., 2002; Kasimanickam et al., 2004; Gilbert et al., 2005; Sheldon et al., 2006, 2009).

In conclusion, expression of $I L 1 B, I L 6, C X C L 8$, and CCL5 did not differ between caruncular and intercaruncular tissue. Samples collected from animals with greater inflammation had greater gene expression than those from animals with zero or medium inflammation. In addition, cytology samples had greater gene expression than biopsy samples in the high inflammation group.

\section{ACKNOWLEDGMENTS}

The study was funded by a project grant to J. P. E. Saut by the Coordenação de Aperfeiçoamento de Pessoal de Nível Superior (CAPES), Conselho Nacional de Desenvolvimento Científico e Tecnológico (CNPq; 428442/2016-1), and Fundação de Amparo à Pesquisa do Estado de Minas Gerais (FAPEMIG; grant APQ00131-15). S. A. Headley, M. E. Beletti, and J. P. E. Saut are recipients of CNPq fellowships.

\section{REFERENCES}

Abdel-Raouf, M., and H. M. Badawi. 1966. Morphological study of uterine caruncles in Egyptian buffalo cows. Zentralbl. Veterinarmed. A 13:252-263. https://doi.org/10.1111/j.1439-0442.1966 .tb00042.x.

Al-Gubory, K. H., M. Arianmanesh, C. Garrel, S. Bhattacharya, P. Cash, and P. A. Fowler. 2014. Proteomic analysis of the sheep caruncular and intercaruncular endometrium reveals changes in functional proteins crucial for the establishment of pregnancy. Reproduction 147:599-614. https://doi.org/10.1530/REP-13-0600.

Barlund, C. S., T. D. Carruthers, C. L. Waldner, and C. W. Palmer. 2008. A comparison of diagnostic techniques for postpartum endometritis in dairy cattle. Theriogenology 69:714-723. https://doi .org/10.1016/j.theriogenology.2007.12.005.

Bogado Pascottini, O., M. Hostens, P. Dini, J. Vandepitte, R. Ducatelle, and G. Opsomer. 2016. Comparison between cytology and histopathology to evaluate subclinical endometritis in dairy cows. Theriogenology 86:1550-1556. https://doi.org/10.1016/j .theriogenology.2016.05.014.

Borges, Á. M., G. D. Healey, and I. M. Sheldon. 2012. Explants of intact endometrium to model bovine innate immunity and inflammation ex vivo. Am. J. Reprod. Immunol. 67:526-539. https://doi .org/10.1111/j.1600-0897.2012.01106.x.

Cardoso, B., M. L. Oliveira, G. Pugliesi, E. O. S. Batista, and M. Binelli. 2017. Cytobrush: A tool for sequential evaluation of gene expression in bovine endometrium. Reprod. Domest. Anim. 52:11531157. https://doi.org/10.1111/rda.13037.

Chapwanya, A., K. G. Meade, F. Narciandi, P. Stanley, J. F. Mee, M. L. Doherty, J. J. Callanan, and C. O'Farrelly. 2010. Endometrial biopsy: A valuable clinical and research tool in bovine reproduction. Theriogenology 73:988-994. https://doi.org/10.1016/j .theriogenology.2009.11.015.

Fischer, C., M. Drillich, S. Odau, W. Heuwieser, R. Einspanier, and C. Gabler. 2010. Selected pro-inflammatory factor transcripts in bovine endometrial epithelial cells are regulated during the oestrous cycle and elevated in case of subclinical or clinical endometritis. Reprod. Fertil. Dev. 22:818-829. https://doi.org/10.1071/ RD09120.

Galvão, K. N., M. Frajblat, S. B. Brittin, W. R. Butler, C. L. Guard, and R. O. Gilbert. 2009. Effect of prostaglandin F2 $\alpha$ on subclinical endometritis and fertility in dairy cows. J. Dairy Sci. 92:49064913. https://doi.org/10.3168/jds.2008-1984.

Galvão, K. N., N. R. Santos, J. S. Galvão, and R. O. Gilbert. 2011. Association between endometritis and endometrial cytokine expression in postpartum Holstein cows. Theriogenology 76:290-299. https://doi.org/10.1016/j.theriogenology.2011.02.006.

Ghasemi, F., P. Gonzalez-Cano, P. J. Griebel, and C. Palmer. 2012. Proinflammatory cytokine gene expression in endometrial cytobrush samples harvested from cows with and without subclinical endometritis. Theriogenology 78:1538-1547. https://doi.org/10 .1016/j.theriogenology.2012.06.022.

Gilbert, R. O., S. T. Shin, C. L. Guard, H. N. Erb, and M. Frajblat. 2005. Prevalence of endometritis and its effects on reproductive performance of dairy cows. Theriogenology 64:1879-1888. https:// doi.org/10.1016/j.theriogenology.2005.04.022.

Herath, S., S. T. Lilly, N. R. Santos, R. O. Gilbert, L. Goetze, C. E. Bryant, J. O. White, J. Cronin, and I. M. Sheldon. 2009. Expression of genes associated with immunity in the endometrium of cattle with disparate postpartum uterine disease and fertility. Reprod. Biol. Endocrinol. 7:55. https://doi.org/10.1186/1477-7827-7-55.

Ireland, J. J., P. B. Coulson, and R. L. Murphree. 1979. Follicular development during four stages of the estrous cycle of beef cattle. J. Anim. Sci. 49:1261-1269. https://doi.org/10.2527/jas1979 $.4951261 \mathrm{x}$

Ishikawa, Y., K. Nakada, K. Hagiwara, R. Kirisawa, H. Iwai, M. Moriyoshi, and Y. Sawamukai. 2004. Changes in interleukin-6 concentration in peripheral blood of pre- and post-partum dairy cattle and its relationship to postpartum reproductive diseases. J. Vet. Med. Sci. 66:1403-1408. https://doi.org/10.1292/jvms.66.1403. 
Kasimanickam, R., T. F. Duffield, R. A. Foster, C. J. Gartley, K. E. Leslie, J. S. Walton, and W. H. Johnson. 2004. Endometrial cytology and ultrasonography for the detection of subclinical endometritis in postpartum dairy cows. Theriogenology 62:9-23. https:// doi.org/10.1016/j.theriogenology.2003.03.001.

Kasimanickam, R., T. F. Duffield, R. A. Foster, C. J. Gartley, K. E. Leslie, J. S. Walton, and W. H. Johnson. 2005. A comparison of the cytobrush and uterine lavage techniques to evaluate endometrial cytology in clinically normal postpartum dairy cows. Can. Vet. J. 46:255-259.

Kaufmann, T. B., M. Drillich, B.-A. Tenhagen, D. Forderung, and W. Heuwieser. 2009. Prevalence of bovine subclinical endometritis $4 \mathrm{~h}$ after insemination and its effects on first service conception rate. Theriogenology 71:385-391. https://doi.org/10.1016/j theriogenology.2008.08.005.

LeBlanc, S. J., T. F. Duffield, K. E. Leslie, K. G. Bateman, G. P. Keefe, J. S. Walton, and W. H. Johnson. 2002. The effect of treatment of clinical endometritis on reproductive performance in dairy cows. J. Dairy Sci. 85:2237-2249. https://doi.org/10.3168/jds S0022-0302(02)74303-8.

Madoz, L. V., M. J. Giuliodori, M. Jaureguiberry, J. Plöntzke, M. Drillich, and R. L. de la Sota. 2013. The relationship between endometrial cytology during estrous cycle and cutoff points for the diagnosis of subclinical endometritis in grazing dairy cows. J. Dairy Sci. 96:4333-4339. https://doi.org/10.3168/jds.2012-6269.

Mansouri-Attia, N., J. Aubert, P. Reinaud, C. Giraud-Delville, G. Taghouti, L. Galio, R. E. Everts, S. Degrelle, C. Richard, I. Hue, X. Yang, X. C. Tian, H. A. Lewin, J.-P. Renard, and O. Sandra. 2009. Gene expression profiles of bovine caruncular and intercaruncular endometrium at implantation. Physiol. Genomics 39:14-27. https: //doi.org/10.1152/physiolgenomics.90404.2008.

Rebourcet, D., F. Odet, A. Vérot, E. Combe, E. Meugnier, S. Pesenti, P. Leduque, H. Déchaud, S. Magre, and B. Le Magueresse-Battistoni. 2010. The effects of an in utero exposure to 2,3,7,8-tetrachloro-dibenzo-p-dioxin on male reproductive function: Identification of Ccl5 as a potential marker. Int. J. Androl. 33:413-424. https:// doi.org/10.1111/j.1365-2605.2009.01020.x.
Salasel, B., A. Mokhtari, and T. Taktaz. 2010. Prevalence, risk factors for and impact of subclinical endometritis in repeat breeder dairy cows. Theriogenology 74:1271-1278. https://doi.org/10.1016/j .theriogenology.2010.05.033.

Saut, J. P. E., G. D. Healey, A. M. Borges, and I. M. Sheldon. 2014. Ovarian steroids do not affect bovine endometrial cytokine or chemokine responses to Escherichia coli or LPS in vitro. Reproduction 148:593-606. https://doi.org/10.1530/REP-14-0230.

Sheldon, I. M., G. S. Lewis, S. LeBlanc, and R. O. Gilbert. 2006 Defining postpartum uterine disease in cattle. Theriogenology 65:1516-1530. https://doi.org/10.1016/j.theriogenology.2005.08 .021 .

Sheldon, I. M., S. B. Price, J. Cronin, R. O. Gilbert, and J. E. Gadsby. 2009. Mechanisms of infertility associated with clinical and subclinical endometritis in high producing dairy cattle. Reprod. Domest. Anim. 44:1-9. https://doi.org/10.1111/j.1439-0531.2009 .01465.x.

Sheldon, I. M., E. J. Williams, A. N. A. Miller, D. M. Nash, and S. Herath. 2008. Uterine diseases in cattle after parturition. Vet. J. 176:115-121. https://doi.org/10.1016/j.tvjl.2007.12.031.

Turner, M. L., G. D. Healey, and I. M. Sheldon. 2012. Immunity and inflammation in the uterus. Reprod. Domest. Anim. 47:402-409. https://doi.org/10.1111/j.1439-0531.2012.02104.x.

Wagener, K., C. Gabler, and M. Drillich. 2017. A review of the ongoing discussion about definition, diagnosis and pathomechanism of subclinical endometritis in dairy cows. Theriogenology 94:21-30. https://doi.org/10.1016/j.theriogenology.2017.02.005.

Walker, C. G., S. Meier, H. Hussein, S. McDougall, C. R. Burke, J. R. Roche, and M. D. Mitchell. 2015. Modulation of the immune system during postpartum uterine inflammation. Physiol. Genomics 47:89-101. https://doi.org/10.1152/physiolgenomics.00098.2014.

Walker, C. G., S. Meier, M. D. Mitchell, J. R. Roche, and M. Littlejohn. 2009. Evaluation of real-time PCR endogenous control genes for analysis of gene expression in bovine endometrium. BMC Mol. Biol. 10:100. https://doi.org/10.1186/1471-2199-10-100. 